\title{
AIDS-Related Services and Training in Outpatient Mental Health Care Agencies in New York
}

Karen McKinnon, M.A. Francine Cournos, M.D. Richard Herman, M.A. James Satriano, Ph.D. Barbara J. Silver, Ph.D. Isela Puello

D irectors of 471 outpatient mental health settings in New York State (82.1 percent of $\mathbf{5 7 4}$ settings located in counties with intermediate to high AID S case rates) completed a survey about HIV and AIDS services, training needs, and barriers to care. Most of the sites served one to ten persons with HIV infection annually and had staff members who were trained in providing at least one H I V-related service. Nonetheless, 84 percent of the respondents reported unmet needs for training. The likelihood of providing certain services was significantly increased in sites that were in urban locations, primarily served clients with comorbid alcohol or other drug use disorders, lacked funds for providing condoms, had staff members who were trained in HIV and AID S services, identified

Ms. McKinnon, D r. Cournos, Mr. Herman, and Ms. Puello are affiliated with the Columbia University C ollege of Physicians and Surgeons and the Washington $\mathrm{H}$ eights Community Service of the New York State Psychiatric Institute, 1051 Riverside Drive, Unit 112, N ew York, N ew York 10032 (e-mail, kmm49@columbia. edu). D r. Satriano is with the Columbia University College of Physicians and Surgeons and the New York State Office of Mental Health. Dr. Silver is affiliated with the Center for M ental Health Services in Rockville, M aryland. particular HIV training needs, believed clients needed condoms, and viewed HIV-related services as very important. (Psychiatric Services 50:1225-1228, 1999)

$M$ ental health care providers now work with clients affected by HIV and AIDS and manage an array of HIV-related problems in their work with these clients. In N ew York City rates of HIV infection among hospitalized psychiatric patients vary from 4 to 23 percent (1). In semirural $\mathrm{N}$ ew York State AID $\mathrm{S}$ is a leading cause of death among young adults with psychotic illnesses (2); patients with comorbid alcohol or other drug use disorders have the highest rates. In some cases, HIV infection occurs in the course of a long-standing psychiatric illness; in others, HIV infection is followed by adjustment difficulties, depression, or neuropsychiatric complications (3). At least 30 percent of all people with HIV require mental health services to treat emotional and cognitive sequelae of the infection (4).

HIV falls uniquely within the purview of mental health care providers. It invades the brain early and can precipitate or alter the appearance of mental illness, and it is spread by unsafe behaviors that mental health care providers often are in the best position to address, along with legal and ethical issues such as duty to warn and duty to protect. I n fact, H IV status now must be considered in assessments of a patient's dangerousness. Finally, adherence to complex antiretroviral regimens may depend on support or enhancement of cognitive and other skills.

Research findings have supported the effectiveness of a variety of services for prevention of H IV transmission and treatment of H IV-related illness. Cognitive-behavioral interventions to reduce risk have been shown to be efficacious with psychiatric outpatients (5). The availability of condoms has been significantly associated with increased condom use (6). $\mathrm{N}$ eedle exchange and other harm-reduction programs have been shown to reduce the likelihood of new HIV infections (7). E arly intervention with combination antiretroviral agents can prolong life and delay the onset of HIV-related illnesses.

Yet we do not know the extent to which front-line mental health care providers are prepared to supply these services. E ven detecting infection is problematic - only 38 percent of infections were recognized across studies that addressed this issue (8). $\mathrm{N}$ or do we know whether certain threshold conditions must be present-for example, providers' having already treated a number of patients with AIDS-before services are viewed as necessary. O nly one study, carried out in N ew York in 1994, has attempted to document HIV and AIDS preparedness in the mental 
health workforce, but a low response rate of 35 percent limited the generalizability of its results (9).

We surveyed outpatient mental health care agencies in New York State about their HIV-related services to describe the specific services provided, the training already acquired by on-site staff and unmet needs for training, and barriers to service provision. We then developed a prediction model to identify determinants of HIV and AIDS service provision, expecting services to vary by regional AIDS case rate, general population density, the number of known AIDS cases within a treatment site, and the proportion of a site's clients with alcohol or other drug use disorders.

\section{Methods}

We selected licensed outpatient mental health treatment sites in counties with intermediate to high rates of AID S cases to examine typical service delivery in settings where the need for HIV-related services might have already influenced providers. Counties with intermediate case rates have between 47.81 and 308 cases per 100,000 population, and those with high case rates have between 308.01 and 2,029.6 cases per 100,000 population (10). An initial listing of 609 eligible sites was obtained from the New York State Office of Mental Health's licensing bureau in 1997. Thirty-five sites (5.7 percent) had ceased operation before they received the survey, leaving 574 eligible sites. Directors or their designees of 471 sites, or 82.1 percent of the 574 sites, completed and returned the survey after up to three written reminders.

The survey comprised 22 items encompassing several domains. Site characteristics included population density, identified as rural, suburban, or urban; county AID S case rates; and number of clients served per year. Client characteristics included the proportion with alcohol or other drug use disorders and the number with known HIV or AIDS treated at the site annually. D ata on training needs included whether staff members had previous training in HIV test counseling or in any other HIV-related ser- vice and whether the site had current needs for training in providing particular H IV-related services.

Attitudes toward the importance of HIV-related services were also assessed. Respondents were asked whether the site provided a range of HIVrelated services, including risk assessment, risk reduction interventions, HIV-test counseling, antibody testing, and condom distribution. Respondents were also asked to describe specific barriers to providing H IV-related services.

Multiple logistic regression analyses were used to identify factors that increased the likelihood that HIV and AIDS services were provided. We first conducted chi square tests to ex-

\section{HIV \\ is spread \\ by unsafe behaviors \\ that mental health care \\ providers often are in \\ the best position \\ to address.}

amine differences between characteristics of sites that provided H IV-related services and identified barriers and those that did not. F or chi square tests with significant results, we calculated unadjusted odds ratios; when the unadjusted odds ratios were significant, we calculated adjusted odds ratios to estimate the likelihood of service provision, simultaneously controlling for the effects of all other variables entered stepwise into the equation.

\section{Results}

Table 1 shows site characteristics and the distribution of HIV-related services provided. We found no significant differences between responding and nonresponding sites in county AIDS case rates. Of the responding sites, 398 sites, or 84.9 percent, were located in counties with high AID S case rates, and 71, or 15.1 percent, were located in counties with intermediate AIDS case rates. A total of 284 of the responding sites, or 60.9 percent, were located in urban areas; 128 sites, or 27.5 percent, were located in suburban areas; and 54 , or 11.6 percent, were located in rural areas. Adjusted odds ratios, 95 percent confidence intervals, and $p$ values are presented for significant results.

The likelihood of providing educational materials to clients was significantly increased when staff were trained in any other HIV-related service besides HIV test counseling ( $\mathrm{OR}=6.92, \mathrm{Cl}=2.27$ to $21.53, \mathrm{p}=.007$ ) and when sites lacked funds for condoms $(O R=5.53, C l=1.56$ to 19.60 , $p=.008$ ).

The likelihood of conducting risk assessment was significantly increased when staff were trained in any other $\mathrm{HIV}$-related service $(\mathrm{OR}=$ 2.27, $\mathrm{Cl}=1.09$ to $4.74, p=.03$ ) and when condoms were viewed as being needed by clients $(\mathrm{OR}=2.46, \mathrm{Cl}=1.11$ to $5.42, p=.03$ ). Routine risk assessment was significantly more likely when staff were trained in any other $\mathrm{HIV}$-related service $(\mathrm{OR}=3.17, \mathrm{CI}=$ 1.24 to $8.08, p=.02$ ).

HIV test counseling was nearly three times as likely when staff were trained to deliver this particular service $(\mathrm{OR}=2.96, \mathrm{Cl}=1.11$ to 7.86 , $p=.03)$, when staff identified a need for this training $(\mathrm{OR}=2.52, \mathrm{Cl}=1.04$ to $6.08, p=.04$ ), and when H IV-related services were viewed as very important or essential $(O R=10.39, \mathrm{Cl}=$ 2.66 to $40.62, p<.001)$. Antibody testing on site was more than three times as likely when staff had training in any other HIV-related service $(\mathrm{OR}=3.08$, $\mathrm{Cl}=1.20$ to $7.89, \mathrm{p}=.02$ ).

The likelihood of a site conducting risk-reduction interventions was increased by more than fourfold when sites lacked funds for condoms $(\mathrm{OR}=$ $4.08, \mathrm{Cl}=1.37$ to $12.14, \mathrm{p}=.011$ ).

The likelihood of providing support groups for HIV-positive clients was increased by more than 30 -fold when sites were in urban areas $(O R=30.49$, $\mathrm{Cl}=3.96$ to $234.91, \mathrm{p}=.001$ ), by more 
than tenfold when the majority of clients had comorbid alcohol or other drug use disorders $(O R=10.18, \mathrm{Cl}=$ 1.96 to $53.00, p=.006)$, and by more than 20 -fold when sites identified a need for staff training in risk interviewing $(\mathrm{OR}=23.64, \mathrm{Cl}=4.04$ to $138.52, \mathrm{p}<.001)$.

Condom distribution was not significantly predicted by any of the factors we measured, but the likelihood that condoms were distributed anonymously was significantly increased, when the majority of clients had alcohol and other drug use disorders ( $O R=6.82, C l=1.34$ to $6.80, p=.009$ ) and when the need for risk-reduction training was identified ( $O R=3.08$, $\mathrm{Cl}=1.44$ to $6.58, \mathrm{p}=.004$ ).

Contrary to our expectations, county AID S case rate, annual numbers of clients served, and known HIV and AID S cases did not predict provision of H IV-related services.

\section{Discussion and conclusions}

This survey represents one of the first attempts to describe the response of the outpatient mental health care system to the AIDS epidemic and to identify predictors of service provision. We found that 85 percent of sites had identified HIV-positive clients and that 70 percent viewed providing HIV-related services as very important or essential. When both these conditions were met, 75 percent of the sites were providing services beyond dispensing information. $H$ aving received $H I V$ training, identifying unmet training needs, and viewing HIV-related services as very important each contributed to particular aspects of service provision.

$M$ aking educational materials available to clients was the HIV and AIDS service most often provided. Such materials are easily disseminated and often are free of charge. However, studies show that knowledge about HIV infection alone has little impact on enacting safer behaviors (6).

L acking funds for condoms resulted in an increased likelihood that educational materials and risk-reduction interventions were provided to clients, suggesting that a greater effort to reach clients may result from both increasing staff readiness and having little recourse to provide con-
Table 1

Characteristics of 471 outpatient mental health care sites in N ew York State that participated in a survey about HIV and AID S services

\begin{tabular}{|c|c|c|}
\hline Characteristic & $\mathrm{N}$ of sites ${ }^{1}$ & $\%$ \\
\hline \multicolumn{3}{|l|}{ Total $\mathrm{N}$ of clients served per year } \\
\hline One to 50 & 35 & 7.6 \\
\hline 51 to 100 & 50 & 10.8 \\
\hline 101 to 200 & 96 & 20.7 \\
\hline 201 to 500 & 120 & 25.9 \\
\hline M ore than 500 & 162 & 35.0 \\
\hline \multicolumn{3}{|l|}{$\begin{array}{l}\text { Percentage of clients with identified alcohol or } \\
\text { other drug use disorders }\end{array}$} \\
\hline None & 8 & 1.7 \\
\hline One to 25 & 197 & 42.1 \\
\hline 26 to 50 & 128 & 27.4 \\
\hline 51 to 75 & 77 & 16.5 \\
\hline 76 to 100 & 58 & 12.4 \\
\hline \multirow{2}{*}{\multicolumn{3}{|c|}{$\begin{array}{l}\text { N umber of clients known to have HIV or AIDS } \\
\text { served annually }\end{array}$}} \\
\hline & & \\
\hline None & 70 & 15.2 \\
\hline One to 10 & 243 & 52.7 \\
\hline 11 to 50 & 92 & 20.0 \\
\hline 51 to 100 & 21 & 4.6 \\
\hline M ore than 100 & 35 & 7.6 \\
\hline \multicolumn{3}{|l|}{ Services provided by site } \\
\hline HIV educational material & 320 & 68.7 \\
\hline HIV risk-reduction interventions & 245 & 53.6 \\
\hline HIV risk assessment & 222 & 48.4 \\
\hline HIV test counseling & 125 & 27.2 \\
\hline Support groups for HIV-positive clients & 88 & 19.2 \\
\hline \multirow{2}{*}{\multicolumn{3}{|c|}{$\begin{array}{l}\text { H IV risk assessment is part of routine intake } \\
\text { procedure }\end{array}$}} \\
\hline & & \\
\hline Yes & 142 & 30.4 \\
\hline No & 152 & 32.5 \\
\hline Only if client reveals H IV risk behavior & 173 & 37.0 \\
\hline \multicolumn{3}{|l|}{ H IV testing of clients who reveal H IV risk behavior } \\
\hline \multicolumn{3}{|l|}{ on intake } \\
\hline Testing done on site & 57 & 12.3 \\
\hline Client referred to external test site & 189 & 40.9 \\
\hline Client referred to hospital or medical clinic & 128 & 27.7 \\
\hline No procedure in place & 88 & 19.0 \\
\hline \multicolumn{3}{|l|}{ Procedures for distribution of condoms } \\
\hline N ot distributed & 273 & 58.8 \\
\hline Clinician distributes & 133 & 28.7 \\
\hline Anonymous distribution & 57 & 12.3 \\
\hline F rom a vending machine & 1 & .2 \\
\hline \multicolumn{3}{|l|}{ Primary barrier to condom distribution } \\
\hline No need & 119 & 34.4 \\
\hline Lack of funds to purchase them & 110 & 31.8 \\
\hline Policy due to religious affiliation & 35 & 10.1 \\
\hline Other policy & 82 & 23.7 \\
\hline \multicolumn{3}{|l|}{ Previous staff training } \\
\hline Pre- and posttest HIV counseling & 249 & 53.8 \\
\hline Other HIV-related services & 246 & 54.3 \\
\hline \multicolumn{3}{|l|}{ Areas in which staff need training } \\
\hline N europsychiatric aspects of HIV and AID S & 334 & 73.7 \\
\hline L egal, ethical, and policy issues & 332 & 72.5 \\
\hline Providing interventions for $\mathrm{H}$ IV risk reduction & 270 & 61.1 \\
\hline HIV risk interviewing & 257 & 57.2 \\
\hline HIV test counseling & 232 & 52.0 \\
\hline \multicolumn{3}{|l|}{$\begin{array}{l}\text { Opinion about importance of H IV-related services } \\
\text { for clients }\end{array}$} \\
\hline E ssential & 185 & 39.8 \\
\hline Very important & 141 & 30.3 \\
\hline Somewhat important & 121 & 26.1 \\
\hline $\mathrm{N}$ ot very important & 15 & 3.2 \\
\hline Unimportant & 3 & .6 \\
\hline
\end{tabular}

1 Total $\mathrm{N} s$ vary due to missing information. 
crete protection to clients in the form of condoms. Respondents at more than one-third of the sites believed there was no need to distribute condoms to clients. N onetheless, risk-reduction interventions are unlikely to be effective if clients lack access to condoms, which are the most effective sexual risk-reduction tool. $\mathrm{M}$ any outpatients cannot afford to purchase them.

Among the sites that provided condoms, the likelihood that they were distributed anonymously was significantly increased when a majority of the clients had alcohol or other drug use disorders and when a site identified the need for training in risk-reduction strategies. Anonymous condom distribution may be more likely to result in clients' having access to condoms than if they have to fill a prescription, ask clinicians, or purchase them.

HIV test counseling was predicted by staff's having received training to conduct it. We did not obtain enough detailed information to allow us to examine specificity effects on other services provided. Test counseling also was predicted by holding the view that HIV-related services are very important. This attitudinal measure did not predict provision of any other service; it is possible that once providers perceive a need for any HIV services among their clients, they first turn to $\mathrm{N}$ ew York's widely available free training programs that lead to certification as an HIV-test counselor.

The factor that predicted provision of the greatest number of H IV-related services was training. Providers who seek training may have greater motivation to offer services, but training also may increase motivation to provide services. Training increased the likelihood that risk assessment was done routinely. At sites where risk assessment was not routine, it was likely to be done only on the basis of clinicians' suspicion of risk, which may be highly subject to error, or after risk behavior became known to staff in some other fashion and perhaps too late for the patient to benefit from primary prevention interventions. In addition to encouraging routine risk assessment, train- ing can increase the expertise with which a specific service is delivered.

Just under one-third of sites provided on-site HIV antibody testing. The presence of this service removes a potential barrier to clients' following through with referral to off-site testing, which usually requires travel and negotiation of a new system but may be preferred by clients with confidentiality concerns.

Contrary to our expectations, the only demographic predictor of service provision was urban setting. E ven after controlling for AID S case rate and number of known cases at a site, urban sites were more than 30 times as likely as suburban or rural sites to provide support groups for H I V-positive clients. H aving a majority of clients with comorbid alcohol or other drug use disorders increased the likelihood of having an HIV-positive client support group.

We relied on program directors or their designees to complete the survey questionnaire and did not assess their motivation to do so or validate the accuracy of their knowledge about HIV and AIDS services within their sites. Programs with staff already committed to providing HIV-related services may have been more likely to complete and return the survey, although our high return rate (82.1 percent) and the lack of a significant difference in regional AIDS case rates between respondents and nonrespondents would reduce the likelihood of this response bias. To increase the completion rate, we asked only a limited number and range of questions. Other HIV-related programmingfor example, linkages to medical care- may have been in place or in development at these agencies. $\mathrm{Fu}$ ture studies that examine the content of services as well as their impact on clients are needed in $\mathrm{N}$ ew York and other AID S-endemic areas.

\section{Acknowledgments}

This study was partly supported by the N ew York State Office of M ental H ealth and contract 96-M 0-2453801D from the Center for $M$ ental $H$ ealth Services. The authors thank Jeannine R. Guido, M.A., for conducting part of the data analysis.

\section{References}

1. Cournos F, M cKinnon K: HIV seroprevalence among people with severe mental illness in the U nited States: a critical review. Clinical Psychology Review 17:259-269, 1997

2. Susser E, Colson P, Jandorf L, et al: HIV infection among young adults with psychotic disorders. American Journal of Psychiatry 154:864-866, 1997

3. M CK innon K, Cournos F : HIV and serious mental illness, in Sexuality and Serious M ental I Ilness. E dited by Buckley PF. Amsterdam, H arwood Academic, 1999

4. Lee HK, Traven S, Bluestone H: HIV-1 in inpatients. Hospital and Community Psychiatry 43:181-182, 1995

5. Kelly JA: HIV risk reduction interventions for persons with severe mental illness. Clinical Psychology Review 17:293-309, 1997

6. Guttmacher S, L ieberman L, Ward D, et al: Condom availability in N ew York City public high schools: relationships to condom use and sexual behavior. American Journal of Public H ealth 87:1427-1433, 1997

7. Interventions to Prevent HIV Risk Behaviors. NIH Consensus Statement 15. Washington, DC, National Institutes of $\mathrm{H}$ ealth, 1997

8. Cournos $F$ : E pidemiology of HIV, in AIDS and People With Severe M ental I IIness: A $\mathrm{H}$ andbook for Mental Health Professionals. E dited by Cournos F, Bakalar N. N ew H aven, Conn, Yale U niversity Press, 1996

9. Satriano J, Rothschild RR, Steiner J, et al: HIV service provision and training needs in outpatient mental health settings. Psychiatric Quarterly 70:73-84, 1999

10. AIDS Surveillance Quarterly Update, AIbany, New York State Department of H ealth, Bureau of HIV/AID S, 1997

\section{Change of Address}

Authors of papers under peer review or being prepared for publication in Psychiatric Services are reminded to notify the editorial office of any changes in address. Please call the editorial office at 202-682-6070, or send updated information by fax to 202-682-6189 or by email to psjournal@psych.org. 